\title{
Integrating ERP (SAP) in the Accounting Curriculum: A Systematic Literature Review and Case Study
}

\section{Yvette Blount (a), Babak Abedin (b), Savanid Vatanasakdakul (c), and Seyedezahra Erfani (c)}

(a) Department of Accounting and Corporate Governance, Macquarie University, Sydney, Australia;

(b) School of Systems, Management and Leadership, University of Technology, Sydney, Australia;

(c) Department of Accounting and Corporate Governance, Macquarie University, Sydney, Australia

\section{Abstract}

This study investigates how an Enterprise Resource Planning (ERP) software package (SAP) was integrated into the curriculum of an Accounting Information Systems (AIS) course in an Australian University. Furthermore, the paper provides a systematic literature review of articles published between 1990 and 2014. The review was conducted to understand how ERP systems are integrated into curriculums of other institutions, and to inform the curriculum designers on approaches for adopting SAP, the benefits and potential limitations. The experiences of integrating SAP into an Accounting Information Systems course from both the students and teaching staff perspectives is described. The paper concludes by proposing critical success factors for integrating ERP effectively into an AIS course.

KEY WORDS: curriculum design, IT competencies, SAP R/3, Australian university 


\section{Introduction}

The design of accounting information systems (AIS) courses including topics covered and software used has been a topic of interest for researchers and instructors for some years (e.g. Tempone, 2012). AIS courses are diverse in the topics they cover. AIS textbooks include different topics or place different emphasis on topics. There is disagreement on the importance of topics and to what extent information systems should be contextualised within accounting or vice- versa (Lane and Porch, 2002; Badua et.al. 2011).

In a 2012 survey in the United States, the major topics covered reported by respondents were internal controls, systems documentation techniques, introduction to systems, COSO, introduction to transaction processing systems, Sarbanes-Oxley (SOX), IT general controls and database management systems (Neely et.al. 2015). The majority of AIS courses included some type of software coverage. Access and Excel were the most common software taught. The courses that used general ledger software predominantly used SAP (Neely et.al. 2015).

This study evaluated the integration of SAP into an accounting information systems (AIS) course at a large Australian university from the perspectives of students and instructors. The study's main research question was:

\section{What are the critical success factors for integrating SAP into an AIS curriculum?}

AIS education underpins the careers of future accountants. The use of accounting software in class aligns with what students are likely to experience in the profession (Boulianne, 2014). Importantly, students should be educated on what the software should do rather than the software itself (Neely et.al. 2015).

Little research evaluates teaching innovations in AIS including what worked well and what did not work. We need a better understanding of how to improve learning using different modes of teaching technologies, for example in-class, computer labs or a combination of these or other modes (Apostolou et.al. 2014).

This study shows that there are significant challenges for students in achieving the learning outcomes using SAP in large classes. A key issue was the technical competencies required for AIS faculty to integrate SAP into the accounting curriculum. This study contributes to the accounting education literature in two ways. The first contribution is the experiences of SAP integration from both the student and the instructors' perspectives, both good and bad, that informs future adoption. The second contribution proposes critical success factors for integrating SAP into the AIS curriculum.

The next section of this paper reviews the literature on ERP and how ERP (usually SAP) is integrated into university curriculums. The following section describes and evaluates the integration of SAP in an accounting information systems (AIS) course in a large Australian university. The paper concludes with proposed critical success factors for successful integration of SAP into the curriculum.

\section{Background}

The extent to which accounting students should be exposed to AIS software is an ongoing debate in the literature. On the one hand, some scholars argue that using AIS software without the necessary understanding of the underlying theories and concepts may not achieve learning outcomes (Boyce, 1999; Gujarathi and McQuade, 1998; Lane and Porch, 2002). Any potential benefits of using AIS software may be lost if students have a negative attitude towards the 
software (Lane and Porch, 2002). This shows that careful consideration of the learning outcomes for using AIS software is important for successful integration into the curriculum.

On the other hand, some scholars have found that integrating accounting software provides students with a more accurate reflection of what occurs in organisations where they will eventually work and better prepares students for the business world and accounting profession (Boulianne, 2014; McDowell and Jackling, 2006). Boulianne (2014) compared the knowledge acquisition of students who completed a case study using software with students who completed the same case study manually. The findings indicate that the hands on benefits of using the software provided learning benefits and enhanced the classroom experience.

Enterprise Resource Planning (ERP) software such as SAP is increasingly utilised in organisations. This indicates that students should have some exposure to this type of software in the Accounting curriculum to better prepare them for the expectations of employers. This requirement aligns with the Learning and Teaching Academic Standards Statement for Accounting that requires Accountants to be able to make sense of information (Australian Deans Council, 2010; Tempone, 2012).

ERP software evolved from Materials Requirement Planning (MRP) and Manufacturing Resource Planning (MRPII) systems from the 1960s through to the 1980s. In 1990, the Gartner Group first developed the acronym Enterprise Resource Planning (ERP) (Dahlen and Elfsson, 1999). ERP integrates and automates core business such as accounting and finance, human resources, manufacturing and sales and marketing. ERP provides information dissemination among all functions within an enterprise (Kumar et al. 2003). ERP systems were designed to integrate silos of information from functional areas such as accounting and finance, human resource management, sales and distribution, project management and logistics to increase efficiency and enhance flexibility (Davenport, 1998; Sanjay et.al. 2013).

In the 1990s ERP systems became the standard for replacing legacy systems in large and multinational organisations (Nazemi et.al. 2012). In the 2000s ERP systems evolved from enhancing operational efficiency to supporting competitive advantage innovations and strategy (Sanjay et. al. 2013). ERP systems share common data in a real time environment that enable management and employees to have a unified view of all business functions across all departments (Kumar et. al. 2003), that is an enterprise-wide view.

Teaching using ERP requires a redesign of the curriculum, rather than an ad hoc approach. In the accounting discipline rather than being taught from a functional, siloed view, students are taught how accounting integrates with all the other functions in an organisation such as marketing and sales, manufacturing, logistics and human resource management (Cannon et. al. 2004). Peslak (2005) found that it is important to include the components of business function fundamentals, processes and management in the curriculum. SAP is one of the largest ERP vendors in the market internationally.

\section{SAP}

SAP, headquartered in Germany, is one of the largest ERP proprietary software vendors globally. SAP has been in business for over forty years, with locations in more than 130 countries. In 2013, SAP retained its market leadership position (Columbus, 2014).

According to the Australian ERP institute (http://www.aerpi.edu.au/sap-skills-shortage/), a critical success factor for the successful adoption of SAP is the availability of skilled ERP resources, of which there is a shortage. To address this shortage of skilled ERP resources, SAP formed the University Alliances Program (UAP) to provide universities with SAP's R/3, 
customised ERP instances, as its ERP system (http://scn.sap.com/community/uac). SAP UAP sponsors ERP training in universities and provides opportunities for students to take part in SAP's R/3 competitions. University students have opportunities to get involved in SAP's R/3 thinking events and projects. SAP offers students online courses leading to SAP's R/3 certifications at a student rate (Antero et. al. 2013).

SAP began in 1972 with the purpose of deploying commercial off the shelf (COTS) applications for real-time data processing. SAP developed the first financial accounting module, SAP R/1, in 1973. SAP R/1 allowed the use of centralized data storage and data maintenance improvement. Three years later, SAP developed SAP R/2, this permitted material management and production planning. From 1992 to 1995 SAP developed and released several versions of $\mathrm{R} / 3$.

SAP R/3 (SAP ERP) encompasses an integrated set of modules, designed in theory to support all aspects of a business including, sales, human resource management, accounting, finance, manufacturing, material management and logistics that enables users to apply an extensive range of integrated business processes (Johnson et. al. 2004, Antero et. al. 2013). SAP provides a SaaS (software as a service) solution for all business sizes called the SAP HANA Cloud Platform. Developing Cloud based applications is important because it is likely that Cloud ERP will outperform traditional ERP in the near future (Chen et. al. 2014).

This section defines ERP, the status of SAP and the process used for selecting papers for the literature review used to inform the integration of SAP into the AIS course in a large Australian university.

\section{Method}

The first phase of the research was a literature review to ascertain the status of ERP software such as SAP into various curriculums, particularly in the Accounting curriculum. The second phase examined the adoption of SAP into the AIS course at a large Australian university from the perspectives of both students and instructors. The students were provided with an opportunity to evaluate the integration of SAP by completing a survey. The instructors completed a reflective journal on their experiences from both technical and pedagogical perspectives.

In the first phase, Kitchenham's (2004) methodology was used to review the literature on how ERP had been adopted in curriculums. Kitchenham's methodology has three phases: planning the review, conducting the review, and reporting the review. The first phase was to plan the review.

\section{Planning the literature review}

The first step was to develop the research questions for the review. We wanted to understand other universities experiences of integrating ERP, particularly SAP into curriculums to better inform our approach. Five (5) research questions were developed to guide the systematic literature review:

RQ1: Which universities have integrated ERP/SAP systems into their curriculum?

RQ2: What activities have universities used to integrate ERP/SAP into their curriculum?

RQ3: What are the stated benefits of integrating ERP/SAP into the curriculum?

RQ4: What issues or limitations were perceived by universities when integrating ERP/SAP into their curriculum? 
RQ5: What are the steps and critical success factors for integrating ERP/SAP into the curriculum?

The second step of planning the review was to develop a protocol. The protocol included the search strategy. This included identifying the search terms, selecting essential resources and databases, selection criteria, study quality assessment checklists, data extraction strategy and the procedures for extracting the information from each study. The purpose for developing the protocol was to decrease the possibility of the researcher's bias.

The third step of planning the review was reviewing the protocol. In this step, three independent experts with expertise in conducting systematic literature reviews assessed the protocol and ambiguities in the protocol were rectified before the review was conducted.

\section{Conducting the review}

The second phase was to conduct the review. The three steps of conducting the review were: develop the search strategy, conduct preliminary searches and select the studies for inclusion. The literature review occurred

\section{Developing the Search Strategy and Preliminary Searches}

A set of search terms were used to address the research questions. The main search terms used were 'ERP systems\#', 'SAP', 'curriculum', 'teaching', 'universities' The symbol (\#) after ERP systems was used to identify words starting with ERP, e.g. ERP systems implementation, ERP systems integration.

The identified search terms were used for the initial search in four major electronic databases: Science Direct, Springer Link, IEEE Explore and Google Scholar. The databases were selected because they included empirical studies and have been used as sources for other studies in the information system discipline. Studies that were published from 1990 to 2013 were included because the 1990s was the key decade for ERP projects (Kumar et al. 2003). A manual search of specific conference proceedings and journal papers from 1990 was also undertaken to ensure that seminal studies were not excluded. The search initially identified 335 articles.

\section{Selecting Studies for Inclusion}

The next step was to filter the relevant studies from the initial pool of 335 articles. This step included two main activities, study selection criteria and the process for selecting the studies for inclusion.

The research questions guided the selection of articles. Articles were selected that explicitly evaluated integrating ERP/SAP into university curriculums. Inclusion and exclusion selection criteria were used to filter those studies that provided direct evidence for the research questions. Two inclusion selection criteria were used: (1) studies that explicitly focused in ERP/SAP integration in university curriculums and (2) studies that were peerreviewed. The three exclusion criteria used were: (1) studies that focused on applying ERP systems in industry, (2) studies that were not written in English, and (3) studies that were not peer-reviewed or were not published as peer-reviewed work.

Abstracts of all 335 papers were reviewed. Using the exclusion criteria, 301 studies were excluded from this study and 34 articles were retained. The full texts of the 34 articles were then reviewed carefully and the two inclusion criteria were used to filter the papers. This resulted in 11 articles. 


\section{Data extraction}

Data extraction forms were developed to effectively summarize the methods and findings from each study to address the research questions. Data was extracted by one of the researchers and checked by another, and when there was a disagreement the issue was discussed until agreement was reached. Data extraction forms included the following items: the source (journal or conference) with full reference, the author(s) information and the country where the study was conducted, summary of the study including activities that academics applied ERP in to their curriculum, results of adopting ERP, issues that were encountered and the approaches used to deal with issues.

\section{Data Synthesis}

The data extraction forms were used to analyse the eleven (11) papers and record key information. Data was tabulated to show:

- Identifying universities that had integrated ERP into their curriculums (RQ1)

- The activities used for integrating ERP into the curriculum (RQ2)

- The stated benefits (RQ3)

- The issues and/or limitations (RQ4)

\section{Search Results}

This section summarizes the results of the analysis. Table 1 shows the title, author/s and year of the eleven (11) articles. Half of the articles (six) were from 1999-2001 which relate to earlier iterations of ERP. There is little research available in more recent years.

\section{Table 1. Search process results}

\begin{tabular}{|c|c|c|}
\hline ID & Title & Author \\
\hline S1 & Using ERP systems in education & Watson and Schneider, 1999 \\
\hline S2 & $\begin{array}{l}\text { Curriculum integration Using Enterprise Resource planning: An Integrative case } \\
\text { approach }\end{array}$ & Cannon et al, 2004 \\
\hline S3 & Integrating ERP in the business school curriculum & Becerra et al,2000 \\
\hline S4 & A Twelve-Step, Multiple Course Approach to Teaching Enterprise Resource Planning & Peslak, 2005 \\
\hline S5 & Integrating SAP R/3 into a College of Business curriculum: Lessons learned & Corbitt and Mensching, 2000 \\
\hline S6 & A Customized ERP/SAP Model for Business Curriculum Integration & Johnson et al, 2004 \\
\hline S7 & SAP student marketplace for the advanced of research and teaching(SAP SMART) & Tracy et al, 2001 \\
\hline S8 & $\begin{array}{l}\text { Enterprise Integration in Business Education: Design and outcomes of Capstone ERP- } \\
\text { based Undergraduate e-Business management course }\end{array}$ & Davis et al, 2004 \\
\hline S9 & Implementing SAP R/3 at the university of Nebraska & Sieber et al, 1999 \\
\hline S10 & Integrating ERP's Second wave into Higher education curriculum & Hawking et al,2005 \\
\hline S11 & Industry-oriented design of ERP-related curriculum an Australian initiative & Stewart and Rosemann, 2001 \\
\hline
\end{tabular}




\section{Approaches Used to Integrate ERP into curriculums}

There were three major themes that emerged from the eleven studies. The first was developing the learning materials for the students. The studies showed the complexity in the development of the learning activities. Instructors had to develop a relationship with the SAP University Alliance coordinator. Instructors had to liaise and coordinate with SAP and the university IT department to ensure that the technical infrastructure and support necessary was available to support students and instructors. SAP through the University Alliance provided a case study and data to develop hands on activities. However, the studies show that instructors developed their own activities and assessments. This may be because the cases and data provided by SAP may not be suitable either technically or pedagogically. The learning outcomes for adopting SAP varied from a focus just on AIS to a more enterprise-wide focus.

The second was the training and development of the instructors. Most studies reported forming a faculty project team to address the technical and pedagogical issues for adopting SAP. Training for instructors typically occurred through the SAP University Alliance. This training incurs a cost. Establishing hands on activities for students including assessment tasks was time consuming.

The third was integrating SAP into the curriculum. Instructors reported difficulty in establishing the hands on activities for integrating SAP into the curriculum. Integration of practical hands on activities with theory was problematic. Hands on experiences of SAP required computer lab access for students and involved curriculum committees.

Appendix 3 provides a summary of the activities for each of the 11 studies.

\section{Benefits and Issues/Limitations of integrating ERP into the curriculum}

The literature review revealed a number of benefits and limitations. The benefits of teaching using ERP, such as SAP is that the focus moves from a narrow AIS view to an enterprise business process view. SAP skills can provide graduates with valuable marketable skills. Hands on activities and assessments are more likely to engage students in an active learning environment.

A major concern was the currency of the skills of the instructors. SAP is complex and it is difficult for instructors to stay current with the skills they need to be confident teaching SAP. Technical difficulties take time to resolve and inconvenience IT support, instructors and students. The knowledge gap for instructors was a recurring theme. The knowledge gap is twofold. The first issue is the software itself. The second issue is the capability of integrating SAP into the curriculum.

Table 2 is a summary of the benefits and issues/limitations identified in the literature. 
Table 2. Benefits and issues of integrating ERP systems

\begin{tabular}{|c|c|}
\hline Benefits & Issues/Limitations \\
\hline $\begin{array}{l}\text { - } \quad \text { Attracting key recruiters to the campus } \\
\text { - } \quad \text { Generating new career opportunities } \\
\text { - } \quad \text { Emerging research opportunities } \\
\text { - } \quad \text { Enhancing learning about business process. } \\
\text { - } \quad \text { busininess educational delivery from functionally oriented to } \\
\text { - } \quad \text { implemg students from general knowledge of ERP to into actual } \\
\text { - } \quad \text { Providing market value to graduate } \\
\text { - } \quad \text { students with IT knowledge } \\
\text { - } \quad \text { Providing active learning environment }\end{array}$ & $\begin{array}{l}\text { - } \quad \text { Battle between academic and skill training due to } \\
\text { knowledge gap } \\
\text { - } \quad \text { Challenge with technical infrastructure to support the } \\
\text { instructional objectives } \\
\text { - } \quad \text { Graduated students with ERP skilled were interested to } \\
\text { - } \quad \text { Sove to Industry rather than to work in academic } \\
\text { - } \quad \text { Getting the right people as trainers; not enough } \\
\text { knowledge } \\
\text { - Hard to fix course content } \\
\text { - } \quad \text { Tnclear vision for integrating ERP in to curriculum } \\
\text { Technical difficulties }\end{array}$ \\
\hline
\end{tabular}

The insights gained from the experiences of others in the literature review findings informed our approach for adopting SAP in an AIS course at a large Australian university. The next section explains the process and provides perspectives from both students and the instructors involved in the course.

\section{Integration of ERP into an AIS course in a large Australian University}

\section{Outline of unit - context}

The AIS unit was a core course for both the Accounting Major and the Business Information Systems Major in the Bachelor of Commerce in the Business Faculty. The course was taught in a two hour lecture and one hour tutorial format. The course typically had an enrolment of between 600 and 800 students.

The topics included the role of accounting information systems, databases, internal controls, business processes, ethics, systems development and information system audit. The course used an accounting lens to explore the issues in the information systems discipline. Students were expected to adopt a critical approach on the role of information systems on the accounting function to understand the critical nexus between the accounting and information systems functions.

The AIS unit as taught in Semester 2, 2012 and Semester 1, 2013 had the following learning outcomes:

1. Understand the role of information systems in general, and accounting information systems specifically, in supporting the operations of an organization.

2. Understand the importance and benefits of systems development methodologies.

3. Prepare and interpret system documentation.

4. Apply internal control techniques to business processes.

5. Examine the role of ethics and ethical decision making within the accounting information systems context.

6. Demonstrate the ability to use an accounting package.

The process of integrating SAP into the course and the assessment tasks are discussed in the following section. 


\section{Process of integrating SAP}

The overarching strategy was integrate SAP into the curriculum by first implementing SAP into the AIS course and moving to other courses as the teaching staff became proficient in the software. A project team consisting of the Head of Department and three academics who convened and taught on the course managed the process and budget.

Two academics, both convenors of the course, attended a SAP week-long course and designed the assessment tasks with assistance with experts from other universities and the SAP academic alliance team.

For students to be able to achieve the learning outcome, 'demonstrate the ability to use an accounting package', the teaching staff had to design a hands-on assessment task. The AIS course had traditionally used an accounting software package to achieve this learning outcome, either MYOB or QuickBooks.

In 2012, SAP replaced QuickBooks. The rationale for replacing QuickBooks with SAP was to provide students with a skill, or at least some experience, in using an ERP package that may provide students with skills that are in demand from employers. The feedback from students was that MYOB and QuickBooks was not providing them with marketable or 'work ready' skills.

The course assessment tasks included an SAP case study (20\%), SAP lab assignment (20\%) and final exam (60\%). Students learnt about SAP from both a VDO case study and lab assessment activities. The assessments were designed to provide students with hands-on SAP $\mathrm{R} / 3$ activities. The overarching aim was for students to develop an understanding of the relationships between business processes and the concepts of ERP. The SAP assessments contributed to the learning outcomes 1,4 and 6 .

A VDO case study on SAP provided the opportunity for students to understand the business environment and to develop critical thinking on the integration issues in a real life business case. The case chosen for the study was the online VDO case on Canada Post's experience of adopting SAP. This was a long case study, which included a background of VDO, their business model and business objectives, business problems related to system integration, and why they considered SAP. The objective of this assignment was for students to individually read the case study and critically analyse it to obtain a good background about applications of ERP/SAP. Students were required to write an analytical report addressing the following questions:

1. Discuss 5 strategic business objectives of the company

2. Discuss 5 challenges that the company is experiencing and 5 opportunities that can be achieved by using SAP

3. Discuss SAP solutions and services that the company has adopted

4. Describe 5 benefits of SAP to the company

The SAP lab assessment was a self-practice assessment on the Global Bike Case study that was made available students on the unit website from week 1 of the semester. It required students to use SAP online materials provided to them in their own time and attempt a number of given activities and questions. SAP was demonstrated to the students in lectures by a guest speaker who was an SAP industry expert. Student support also included interactive online tutorials as well as a series of exercises and solutions in the Financial Accounting module of the Global Bike Case study. Students could also access the practice sets in their own time. In addition, computer labs were booked and lab demonstrators were provided to assist students on their hands-on experience with SAP. Support from the lab demonstrators was provided two weeks before the assessment task was due. 


\section{Student perspectives}

Students were asked to complete an online survey on their experiences of using SAP R/3 over two semesters (Semester 2, 2012 and Semester 1, 2013) during the last week of the semester. A copy of the survey is provided in Appendix 1. Surveys were conducted on a voluntary basis and the identity of survey participants was anonymous. This was to ensure that students were free to express their opinions and that they did not feel there would be any implications on their grades. The results of the survey were used to inform decisions about the appropriateness of using SAP ERP software in this course and how SAP could be further integrated into the program to improve the curriculum.

The student enrolment in semester 2, 2012 was 650. Semester 1, 2013 was higher with 700 students. There were 66 percent of international students enrolled in semester 2, 2012 and 52 percent in semester 1, 2013. Ninety nine percent (99\%) of students were enrolled full-time basis for both semesters. The average students' GPAs in semester 2, 2012 was 2.68 out of 4, while semester 1, 2013 was 2.33. Approximately ten percent (10\%) of students participated in the surveys over both semesters.

The findings from the survey showed that a large portion of students in both semesters reported enjoying the SAP experience. A small number, fifteen percent (15\%), of participants was not satisfied with the SAP assessment and recommended that the assessment not be used in the future. The reason behind the dissatisfaction of this small group of students may be partly explained by the student's difficulty in using the instructions for the assessment. Twenty six percent $(26 \%)$ of students needed clarification and more detailed information about the assessment task. However, the results in semester 1, 2013 showed the dissatisfaction rate was reduced to seven per cent $(7 \%)$ and the satisfaction rate increased to seventy one percent $(71 \%)$. This may be explained by the additional support provided to the students as well as the instructors increased familiarity with the software.

This course traditionally had a significantly high failure rate. One of the success factors was the improvement in student grades. The success rate improved in Semester 2, 2012 and Semester 1, 2013 from previous semesters. The failure rate in semester 1, 2013 and semester 2, 2012 was nine percent (9\%). For example, the failure rated in semester 1, 2012 was thirteen percent and in Semester 2, 2011 the failure rate was eighteen percent (18\%). This is an improvement of fifty percent $(50 \%)$.

Table 3 summarises students' perspectives about their experience of using SAP. Students generally enjoyed the teaching material. The SAP assessments allowed students to access and practice SAP free of charge and enhance their resume for their future careers. However, some students found it difficult or time consuming to familiarise themselves with the SAP user interface. Some required more detailed instructions for using the software which suggests that the software is not intuitive and requires specific instruction.

Table 3. Student perspectives on using SAP R/3

\begin{tabular}{|l|l}
\hline Benefits & Issues/Limitations \\
\hline
\end{tabular}




\begin{tabular}{|c|c|}
\hline $\begin{array}{l}\text { - Students in general enjoyed this SAP assessment task as they } \\
\text { believed it would help them in finding jobs } \\
\text { The resources (e.g. interactive tutorials and sample questions) } \\
\text { were useful } \\
\text { The opportunity to work with SAP free of charge was } \\
\text { appreciated, as it is not feasible for many people to access SAP } \\
\text { free of charge } \\
\text { Students found that materials provided for their hands-on } \\
\text { experiences of SAP are useful including the demos and videos }\end{array}$ & $\begin{array}{l}\text { - The instructions for doing the assessment could have } \\
\text { been clearer } \\
\text { Some students found it difficult to use SAP interface to } \\
\text { find particular links, and to know where to go for } \\
\text { additional help }\end{array}$ \\
\hline
\end{tabular}

\section{Course Convenor/instructor perspectives (reflections)}

There were a number of challenges using SAP in teaching. The implementation was particularly challenging when delivering SAP to students in a large class. The first challenge from teaching staff perspectives was the amount of time and effort needed for the design of SAP assessments and developing the teaching materials. The clarity and the level of detailed information that needed to be provided to students played a critical role, especially as it was a self-practice task. The teaching team mitigated this challenge by providing a number of interactive learning materials such as online demonstrations, tutorials and exercises that could be done independently. This is similar to the findings from the literature review where this was a recurring theme.

A second challenge was the amount of time required to communicate with SAP University Alliance staff members to generate usernames and passwords for students and to set up the software in the laboratories for students to use. The way the teaching staff dealt with issues was to obtain support from an external assistant for dealing with administrative issues such as username/passwords, especially for very large teaching environment in this case study. In addition to this, positive feedback was received from students when this external contact provided face-to-face support in the laboratories to answer students' questions. However, this was costly because extra resources were employed to support the teaching staff.

Students' computer literacy was another challenge. While the teaching staff assumed that all students knew how to use computers for accessing SAP, many students had difficulty in doing some basic computer tasks such as activating their user IDs for the first time, changing their password, or saving their files for future use. While support was provided to students through a once a week face- to- face consultation, a large number of students' issues had to be resolved through long emails and phone conversations.

Technical challenges with installation and implementation of SAP on the University's computer labs was another challenge. In the first semester of the trial, Semester 2, 2012, SAP was only available in the University's computer labs. Thus students had to travel to the University to attempt assignment questions and complete their task/s (rather than access the program from home or work). This caused difficulties for students, for example there were not enough computers available in the labs close to the submission due date. However, this issue was later fixed by the University's IT department. In the second semester of the trial, students were able to remotely connect to the labs and access SAP.

\section{Critical success factors for integrating ERP into the curriculum}

The critical success factors for integrating SAP into the curriculum of an AIS course from the perspectives of the course convenor/teaching staff are informed by the systematic literature review and the experience of integrating SAP into an AIS course at a large Australian university. 


\section{Support and commitment from top management}

The first critical success factor is strong leadership and support from top management. Both the literature review and our experience indicate that support from top management plays an integral role in the success of ERP integration into the curriculum. Top management support is essential for access to resources including financial resources for training and development and technology. The project/teaching team should communicate with management on the issues to facilitate timely decision making (Young et. al. 2013). The project scope and how ERP will be integrated into the curriculum must be clearly defined at the start of the project (Watson and Schneider, 1999; Davis et. al. 2004).

\section{ERP faculty committee}

The second critical success factor is to form a committee consisting of teaching academics, technology specialists and management. The literature provides evidence that forming a faculty committee to integrate ERP into the curriculum is an important factor for success. The team should be multi-skilled, composed of academic and technical people. The committee should be responsible for the overall schedule for ERP integration including checking the availability of necessary resources, introducing ERP into the curriculum, setting up the technical infrastructure and monitoring and assessing whether the ERP system has met the student learning outcomes.

\section{Education and training}

Education and training for the faculty ERP committee, particularly the teaching and technical staff is a third critical success factor. The teaching staff require training in both the software (because SAP is not intuitive) and how to effectively develop assessment tasks including marking. Integrating ERP into the curriculum requires that the teaching staff establish a clear and compelling learning outcome for students. Introducing students to business functions and business processes, exposure to ERP systems, implementing case studies, providing hands on ERP module training are valuable skills for the workplace.

Monitoring and assessing the effectiveness of integrating ERP Systems into the curriculum

The effectiveness of integrating ERP systems into the curriculum needs to be assessed against the learning outcomes. Conducting student surveys and interviews can provide insights into how effectively the learning outcomes are being met. The feedback provides input into reflective practice around teaching. This reflection should lead to corrections and modifications for achieve the learning outcomes.

\section{Agenda for Future Research}

This systematic literature review summarised the empirical studies that explicitly outlined experiences of integrating ERP systems into university curriculums. However, we were unable to find any major studies in a developing country. This may be because developing countries do not have the resources to implement SAP or any other ERP system. Future research is therefore needed to investigate this area and compare the implementation of ERP systems in developing versus developed nations.

While our initial literature review located a large number of papers on adopting ERP (335 articles) in the curriculum, a lot of these studies were excluded from our review because they did not include empirical findings or had not systematically documented their experience with ERA implementation. Future studies of integration of ERA into the curriculum therefore need 
to use frameworks or systematic ways to more effectively document and present their findings, and also consider using empirical results to support subjective and/or qualitative findings.

One finding of this was the importance of the level of training that needs to be provided to the SAP instructors. We found that it is essential to properly develop skills and capabilities of academics that will be involved in teaching SAP content in their classes. Yet, it was out of the scope of this current paper to investigate the specific roles and skills that need to be considered for effective training of SAP instructors. Future studies therefore can investigate such roles, and suggest specific strategies that for developing academics capabilities for teaching ERA/SAP software to the undergraduate and/or postgraduate students.

We also found that students were very keen to use SAP as part of the curriculum for developing skills and capabilities that make them more 'work ready' after graduation. Students in particular enjoyed the exposure to SAP, as they were hoping this knowledge would add their chance to find a job after graduation. However, given the size of ERP/SAP software and their capabilities, the question is to what extent the content of ERP/SAP should be integrated into an undergraduate or postgraduate course. Future research is needed to investigate factors that would impact how much ERA/SAP content should be integrated into existing courses.

Lastly, while SAP provides a lot of resources for academic teaching and learning, we found these resources have very limited flexibility to be adopted and/or changed for different courses and for different institutions. This is a challenging issue for instructors, specially for larger environment, and therefore future research is needed to investigate alternative ways for structuring and preparing resources for teaching ERP content in accounting information system courses.

\section{Conclusion}

According to the feedback obtained from students, ERP integration into the curriculum has positive outcomes for academic institutions. The findings of this study show that preparation of the assessment task and the level of detailed guidance available to students are critical factors for successfully integrating SAP into the curriculum. Our results also show that, depending on the size of the course, ongoing support needs to be provided to deal with students' questions about SAP tasks as well as with administrative and technical issues. This is largely because SAP is not intuitive.

The literature review showed SAP as the key ERP vendor used by universities for teaching ERP. The SAP University Alliance is successful in encouraging universities to incorporate SAP/R3 ERP, into their curriculums.

\section{Next Steps}

I think we need a section here on what we did next - did we continue with SAP/discontinue $\mathrm{SAP} /$ what we did next etc.

We are constantly upgrading our teaching approach using experiences in implementing SAP to AIS curriculum. Although evidence shows that SAP has provided great benefits to 
students. Implementing SAP assignment also has limitation as it does not provide individual assignment for each student and this leads to plagiarism cases. This is challenging for instructors to control in the large teaching class environment. Therefore, other AIS applications are being investigated as an alternative. For example, we are investigating the possibility to implement online teaching stimulation on Xero for cloud based AIS application, MYOB with online tutorials, unique assignment for individual student and instant online marking with feedback. 


\section{Appendix 1: SAP Experience Survey}

1. Please provide the following information about this course

\section{Course Name:}

Course Number:

Your Lecturer's Name:

2. Please rate your level of satisfaction with each of the following aspects of the resources?

( 1 very satisfied...5 very unsatisfied)

\begin{tabular}{|c|c|c|c|c|c|}
\hline$\#$ & Question & $\begin{array}{c}\text { Very } \\
\text { Dissatisfied }\end{array}$ & Dissatisfied & Neutral & Satisfied \\
\hline 1 & $\begin{array}{l}\text { Relevancy of the material } \\
\text { to the course }\end{array}$ & & & & \\
\hline 2 & Interactive PDFs & & & & \\
\hline 3 & Videos / Demos & & & & \\
\hline
\end{tabular}

3. Rate your overall satisfaction with these resources ( 1 very satisfied...5 very unsatisfied)

4. Do you have comments about the usefulness of these resources?

5. Would you say that the materials provided were...? (1 very difficult to follow...5 very easy to follow)

6. Were there any areas you found particularly difficult to follow and/or understand? If so, please explain.

7. What, if anything, would you change about these resources to make them more helpful to you in studying and learning the material?

8. Based on what you have seen, how likely would you be to recommend these resources to your lecturer for use in future classes? (1 very likely....5 very unlikely) 


\section{Appendix 2: Countries and Universities that have integrated ERP into}

the curriculum

The majority of universities (9) were located in the USA, followed by Australia (3) and Canada (1).

\begin{tabular}{|c|c|c|}
\hline ID & Country & University \\
\hline S1 & USA & Louisiana State University \\
\hline S2 & USA & Grand valley \\
\hline S3 & USA & Florida International University \\
\hline S4 & USA & Penn State \\
\hline S5 & USA & California State University \\
\hline S6 & USA & Northern Arizona University \\
\hline S7 & USA and Australia & South American University and Australian University \\
\hline S8 & Canada & University of New Brunswick \\
\hline S9 & USA & University of Nebraska-Lincoln \\
\hline S10 & Australia & Victoria University \\
\hline S11 & Australia & Queensland university of technology \\
\hline S12 & USA & Arcadia University \\
\hline
\end{tabular}




\section{Appendix 3: Approaches Used to Integrate ERP into curriculums}

\begin{tabular}{|c|c|}
\hline Study & Type of Activity \\
\hline $\mathrm{S} 1$ &  \\
\hline $\mathrm{S} 2$ & $\begin{array}{ll}\text { - } & \text { Installing Data systems'(SAP)R/3 } \\
\text { - } & \text { Training faculty members through SAP administrated courses } \\
\text { - } & \text { Applying International Demonstration and Education System(IDES)for exercises } \\
\text { - } & \text { Adopting experiences of other universities } \\
\text { - } & \text { Using factious model company and its simultaneous implementation in an ERP system } \\
\text { - } & \text { Replacing IDES with a more manageable company(SSB) } \\
\text { - } & \text { Forming cross functional team of faculty member } \\
\text { - } & \text { Implementing SSB in SAP configuration training } \\
\text { - } & \text { Applying introductory case in various course } \\
\text { - } & \text { Integrating the core undergraduate curriculum through newly developed SBB }\end{array}$ \\
\hline $\mathrm{S} 3$ & $\begin{array}{ll}\text { - } & \text { Forming project team } \\
\text { - } & \text { Providing introductory courses to a few team members } \\
\text { - } & \text { Developing In house training by team members } \\
\text { - } & \text { Receiving complimentary copy of SAP's R/3system. } \\
\text { - } & \text { Offering ERM with strong focus on business process course (undergraduate -post }\end{array}$ \\
\hline $\mathrm{S} 4$ & $\begin{array}{ll}\text { - } & \text { Introducing basic concept of business and management } \\
\text { - } & \text { Educating business function } \\
\text { - } & \text { Educating business processes } \\
\text { - } & \text { Live demonstration of SAP R/3 } \\
\text { - } & \text { Study of theory of ERP } \\
\text { - } & \text { Developing Hands on activities } \\
\text { - } & \text { Hands on module exploration } \\
\text { - } & \text { New SAP R/3 company setup } \\
\text { - } & \text { Setup of necessary ancillary hardware/software -theory } \\
\text { - } & \text { Standard reporting for SAP }\end{array}$ \\
\hline S5 & $\begin{array}{ll}\text { - } & \text { Forming faculty team } \\
\text { - } & \text { Providing basic background on business function } \\
\text { - } & \text { Organizing technical infrastructures } \\
\text { - } & \text { Organizing workshop } \\
\text { - } & \text { Exposure to SAP R/3 }\end{array}$ \\
\hline S6 & $\begin{array}{ll}\text { - } & \text { Applying International Demonstration and Education System(IDES)for exercises } \\
\text { - } & \text { Applying case study approach integrated with the SAP R/3 business process } \\
\text { - } & \text { Reproducing an actual company (Sun Ocean Sand)in the SAP system } \\
\text { - } & \text { Applying Hands on activities }\end{array}$ \\
\hline S7 & $\begin{array}{ll}\text { - } & \text { Creating SAP student marketplace } \\
\text { - } & \text { Forming collaborative curriculum committees } \\
\text { - } & \text { Demonstrating business process } \\
\text { - } & \text { Applying hands-on activities } \\
\text { - } & \text { Creating the pedagogical materials for use in classes } \\
\text { - } & \text { Defining and selecting ERP Smart industry } \\
\text { - } & \text { Exposing students to many learning experiences in business }\end{array}$ \\
\hline
\end{tabular}




\begin{tabular}{|c|c|}
\hline S8 & $\begin{array}{ll}\text { - } & \text { Receiving training workshop through SAP University Alliance } \\
\text { - } & \text { Exposure to SAP R/3 } \\
\text { - } & \text { Combination of management leaning with hands-on lab component } \\
\text { - } & \text { Training workshops by Dolphin Group } \\
\text { - } & \text { Focusing on organizational process } \\
\text { - } & \text { Applying business case(respond to request seeking to invest in ERP system) }\end{array}$ \\
\hline S9 & $\begin{array}{ll}\text { - } & \text { Introducing basic concept of business and management } \\
\text { - } & \text { Educating business processes } \\
\text { - } & \text { Exposure to SAP R/3 } \\
\text { - } & \text { Developing Hands on activities }\end{array}$ \\
\hline $\mathrm{S} 10$ & $\begin{array}{ll}\text { - } & \text { Introducing business functions } \\
\text { - } & \text { Introducing business process } \\
\text { - } & \text { Implementing case studies } \\
\text { - } & \text { Setting necessary hard ware/software } \\
\text { - } & \text { Applying industry-based projects with focusing on ERP in curriculum } \\
\text { - } & \text { Forming partnerships with international education institutions } \\
\text { - } & \text { Developing ongoing collaboration with industry } \\
\text { - } & \text { Applying Hands on SAP R/3 module training }\end{array}$ \\
\hline S11 & $\begin{array}{ll}\text { - } & \text { Developing Hands on activities } \\
\text { - } & \text { completing virtual SAP projects } \\
\text { - } & \text { integrating the practical expertise with their theoretical subjects } \\
\text { - } & \text { Using lab with hands-on access to SAP software } \\
\text { - } & \text { offering self-paced online program }\end{array}$ \\
\hline
\end{tabular}




\section{References}

Al-Mashari, M., Al-Mudimigh, A., \& Zairi, M. (2003). Enterprise resource planning: taxonomy of critical factors. European journal of operational research, 146(2), 352-364.

Antero, M. C., Hedman, J., \& Henningsson, S. (2013). Evolution of business models: A case study of SAP.

Apostolou, B., Dorminey, J.W., Hassell, J.E., Rebele, J.E., (2014) A summary and analysis of education research in accounting information systems (AIS) Journal of Accounting Education, 32 (2) pp. 99- 112

Apostolou, B., Dorminey, J.W., Hassell, J.E., Rebele, J.E., (2015) Accounting education literature review (2013-2014) Journal of Accounting Education, 33 (2) pp. 69-127

Australian Deans Council (2010) Learning and Teaching Academic Standards Project Business, Management and Economics Learning and Teaching Academic Standards Statement for ACCOUNTING December 2010 http://www.abdc.edu.au/data/Accounting_LS/Accounting_Learning_Standards_February_2011.pdf viewed 7 September 2015

Badua, F. A., Sharifi, M., \& Watkins, A. L. (2012). The topics, they are a-changing: The state of the accounting information systems curriculum and the case for a second course. The Accounting Educators' Journal, 21(1).

Becerra-Fernandez, I., Murphy, K. E., \& Simon, S. J. (2000). Enterprise resource planning: integrating ERP in the business school curriculum.Communications of the ACM, 43(4), 39-41.

Boulianne , Emilio (2014) Impact of accounting software utilization on students' knowledge acquisition: An important change in accounting education, Journal of Accounting \& Organizational Change, Vol. 10 Iss: 1, pp.22-48

Boyce, G. (1999), Computer-assisted teaching and learning in accounting: pedagogy or product?, Journal of Accounting Education, Vol. 17 Nos 2/3, pp. 191-220.

Cannon, D. M., Klein, H. A., Koste, L. L., \& Magal, S. R. (2004). Curriculum integration using enterprise resource planning: An integrative case approach. Journal of Education for Business, 80(2), 93-101.

Chen, C. S., Liang, W. Y., \& Hsu, H. Y. (2014). A Cloud Computing Platform for ERP Applications. Applied Soft Computing.

Columbus, Louis (2014) Gartner's ERP Market Share Update Shows The Future Of Cloud ERP Is Now http://www.forbes.com/sites/louiscolumbus/2014/05/12/gartners-erp-marketshare-update-shows-the-future-of-cloud-erp-is-now/ viewed 14 December 2014.

Corbitt, G., \& Mensching, J. (2000). Integrating SAP R/3 into a College of Business curriculum: Lessons learned. Information Technology and Management, 1(4), 247-258.

Davis, C. H., \& Comeau, J. (2004). Enterprise integration in business education: Design and outcomes of a capstone ERP-based undergraduate e-business management course. Journal of Information Systems Education, 15(3), 287-300.

Davenport, T.H. (1998), Putting the enterprise into the enterprise system, Harvard Business Review, Vol. 76 No. 4, pp. 121-131.

Dahlen, C., Elfsson, J., 1999. An Analysis of the Current and Future ERP Market with Focus on Sweden. The Royal Institute of Technology,Stockholm.

Deming, W.E. 1986.Out of the Crisis. MIT Press. Cambridge, MA, page 88

Erfani, S. Z., Akhgar, B., \& Ramin, F. (2010). A novel knowledge management implementation model for mobile telecommunication industry. World Appl Sci J, 11(1), 29-37.

Esteves, J., \& Pastor-Collado, J. (2001). Analysis of critical success factors relevance along SAP implementation phases. 
Gable, G. G., Scott, J. E., \& Davenport, T. D. (1998). Cooperative ERP life-cycle knowledge management.

Gujarathi, M.R. and McQuade, R.J. (1998), Problems and considerations in implementing technology-based solutions to address changes in accounting curricula, Advances in Accounting Education, Vol. 1 No. 1, pp. 1-23.

Hejazi, S. S., Halpin, A. L., \& Biggs, W. D. (2014). Using SAP ERP technology to integrate the undergraduate business curriculum. Developments in Business Simulation and Experiential Learning, 30.

Hawking, P., McCarthy, B., \& Stein, A. (2005). Integrating ERP's second wave into higher education curriculum.

Johnson, T., Lorents, A. C., Morgan, J., \& Ozmun, J. (2004). A customized ERP/SAP model for business curriculum integration. Journal of Information Systems Education, 15(3), 245-254.

Kitchenham, B. (2004). Procedures for performing systematic reviews. Keele, UK, Keele University, 33, 2004.

Kumar, V., Maheshwari, B., \& Kumar, U. (2003). An investigation of critical management issues in ERP implementation: Empirical evidence from Canadian organizations. Technovation, 23(10), 793-807.

Lane, A. and Porch, M. (2002), "Computer aided learning (CAL) and its impact on the performance of non-specialist accounting undergraduates", Accounting Education: An International Journal, Vol. 11 No. 3, pp. 217-233.

Loizos, C (1998), ERP: Is it the ultimate software solution, Industry Week, 7 ,p. 33Monk, E., \& Wagner, B. (2012). Concepts in enterprise resource planning. Cengage Learning.

McDowall, T. and Jackling, B. (2006), The impact of computer-assisted learning on academic grades: an assessment of students' perceptions, Accounting Education: An International Journal, Vol. 15 No. 4, pp. 377-389.

Momoh, A., Roy, R., \& Shehab, E. (2010). Challenges in enterprise resource planning implementation: state-of-the-art. Business Process Management Journal, 16(4), 537-565.

Nazemi, E., Tarokh, M., \& Djavanshir, G. (2012). ERP: a literature survey. International Journal Of Advanced Manufacturing Technology, 61(9-12), 999-1018

Neely, Pam; Forsgren, Nicole; Premuroso, Ron; Vician, Chelley; Clinton E. White, Clinton E. (2015) Accounting Information Systems (AIS) Course Design: Current Practices and Future Trajectories Communications of the Association for Information Systems, Vol.36, p.599

Peslak, A. R. (2005). A twelve-step, multiple course approach to teaching enterprise resource planning. Journal of Information Systems Education, 16(2), 147.

Rebele, J.E., St Pierre, E.K., (2015) Stagnation in accounting education research, Journal of Accounting Education, 33 (2), pp 128-137

Rockart, John F., "Chief executives define their own data needs", Harvard Business Review 1979 (2), pages 81-93.

Sanjay Mathrani, Anuradha Mathrani, Dennis Viehland, (2013) "Using enterprise systems to realize digital business strategies", Journal of Enterprise Information Management, Vol. 26 Iss: 4, pp.363 - 386

Sieber, T., Siau, K., Nah, F., \& Sieber, M. (1999). Implementing SAP R/3 at the University of Nebraska. ICIS 1999 Proceedings, 77.

Singh, V. K. (2013). PDCA Cycle: A Quality Approach. Utthan-The Journal of Management Sciences, 1(1).

Stewart, G., \& Rosemann, M. (2001). Industry-oriented design of ERP-related curriculum-an Australian initiative. Business Process Management Journal, 7(3), 234-242. 
Tempone, Irene., Kavanagh, Marie., Segal, Naomi., Hancock, Phil., Howieson, Bryan., Kent, Jenny (2012) "Desirable generic attributes for accounting graduates into the twenty-first century: The views of employers", Accounting Research Journal, Vol. 25 Iss: 1, pp.41 55

Tracy, S., Stewart, G., Boykin, R., Najm, M., Rosemann, M., \& Carpinetti, L. (2001). SAP Student Marketplace for the Advancement of Research and Teaching (SAP Smart). AMCIS 2001 Proceedings, 195.

Umble, E. J., Haft, R. R., \& Umble, M. M. (2003). Enterprise resource planning: Implementation procedures and critical success factors. European journal of operational research, 146(2), 241-257.

Velcu, O. (2010). Strategic alignment of ERP implementation stages: An empirical investigation. Information \& Management, 47(3), 158-166.

Watson, E. E., \& Schneider, H. (1999). Using ERP systems in education. Communications of the AIS, 1(2es), 3.

Young, R., \& Poon, S. (2013). Top management support—almost always necessary and sometimes sufficient for success: Findings from a fuzzy set analysis. International Journal of Project Management, 31(7), 943-957.

Zhang, Z. and H. Sharifi, 2007. Towards theorybuilding in agile manufacturing strategy Ataxonomical approach. IEEE Transactions onEngineering Management EM, 54(2): 351370. 